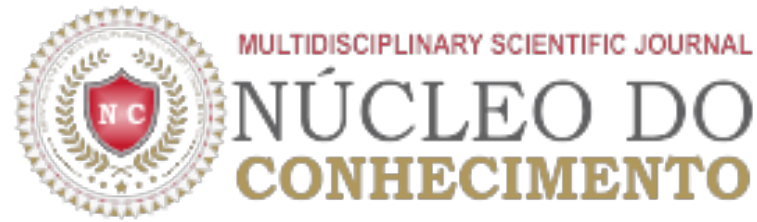

\section{Prevalence of Depressive Symptoms in Nursing Academics at a Private School in Belém-PÁ}

TRINDADE, Fábyla d' Tácia Brito [1]

GOMES, Nathalia Neves [2]

FERREIRA, Sandra Elizia Gonçalves [3]

MORAIS, Elisângela Claudia de Medeiros [4]

OLIVEIRA, Margaret de [5]

DENDASCK, Carla Viana [6]

OLIVEIRA, Euzébio de [7]

TRINDADE, Fábyla d' Tácia Brito; et.al. Prevalence of Depressive Symptoms in Nursing Academics of a Private School in Belém-PÁ. Multidisciplinary Scientific Journal. Special Edition of Health. Year 02, Vol. 04. Issue 11, pp. 24-38, November of 2017. ISSN:2448-0959

\begin{abstract}
The purpose of this article was to identify the prevalence of depressive symptoms in nursing students in the 1st, 4th and 8th periods of a private college in Belém-Pa. Exploratory quantitative approach research and the instrument used was the Back-1l Depression Inventory. In a sample of 147 academics, 69 (46.94\%) did not present depressive symptoms, 42 (28.57\%) presented mild symptoms, 31 (21.08\%) presented moderate symptoms and $5(3.40 \%)$ had severe symptoms . Most academics presented indicative of mild to moderate depression symptoms. A greater change was observed in the results of the 8th period, which, to a certain extent, is in agreement with other studies carried out with students of the health area, for this phase of the course. It is also important to highlight a high index of symptoms of severe depression in the first period. From the results obtained, it was possible to observe the need for psychological attention to nursing students of all periods, aiming to offer support to deal with situations of psychological distress.
\end{abstract}


Keywords: Depression, Nursing Course Academics, Beck II Depression Inventory.

\section{INTRODUCTION}

Depression "a disease of the present time" this term has been widely used in scientific circles and disseminated in the media. Initially, the symptoms of sadness, anxiety, and suicidal tendencies were called melancholy. A term created more than 25 centuries ago, designated symptoms or characterized mental states. From the seventeenth century onwards, there were several transformations, among them the replacement of the term melancholia with depression and psychiatry emerged as a medical specialty. Throughout the twentieth century, several terms have been studied and debated, such as the question of the endogenous or exogenous nature of depression and the unipolar and bipolar terms. Perhaps the most striking of the changes has been to consider depression as a disease or affective or mood disorder (MAXWUELL, 2010).

Generally, this disease consists of a universal mental disorder, whose main disturbance is the change of the humor or the affection. The mood swings reflect negatively on all activities of the affected person. Loss of productivity, loss of interest and lack of initiative both at work and in the study, are symptoms that cause serious social harm to the patient. In the face of these syndromes, Depression is considered a public health problem. In the twenty-first century, depression has been responsible for the highest burden of disease among those characterized by mental disorder. The overload is not only for the individual who suffers, but also for their relatives and caregivers (MOREIRA; FUREGATO, 2013).

The World Health Organization estimates that there are 350 million people living with depression in the world and is expected to affect more people than any other health problem in the coming years, including cancer and heart disease. Depression usually has a high cost, not only in financial terms, but can also cost relationships, jobs, and even life itself (BEES, 2014).

In Brazil data from the Brazilian Institute of Geography and Statistics (IBGE) show that depression is the fourth most diagnosed chronic disease, followed by hypertension and cancer. About $42 \%$ are assisted in private practices and $33.2 \%$ use the basic health unit, generating high economic and social costs for the Government (IBGE, 2013).

A population that deserves attention, because it is in contact with the psychic suffering, is that of students and health professionals. This part of society is constantly marked by uncertainties and anxieties, which must be carefully considered, since when they are experienced, they reveal their own feelings, as well as the difficulty in managing them. These situations provoke a shock reaction between the "good" and the "bad", generated mainly by the anguish resulting from the individual's maladaptation in the face of a new situation (OLHER, 2012).

WHO data reveal that depression is a public health case in all regions of the world. Studies show that half of Brazilian university students experienced some type of emotional crisis in 2011, where depression was the most representative: reaching about $15 \%$ of students (SIMAS, 2012).

In view of this situation, we present this work that aims to highlight the importance of identifying the prevalence (number of cases in a given population) of depressive symptoms among the academics of the Amazon Metropolitan College (FAMAZ), and to alert need to elaborate actions that aim to offer greater 
care and guidance so that the student can deal with the psychic problem.

\section{MATERIAL AND METHODS}

The present study is a research of quantitative approach of exploratory character.

The instrument applied was the Beck II - BDI-II Depression Inventory. Refers to sadness, pessimism, past failure, loss of pleasure, guilt, feelings of punishment, self-esteem, self-criticism, suicidal thoughts or desires, crying, agitation, loss of interest, indecision, devaluation, changes in sleep patterns, irritability, appetite changes, concentration difficulties, fatigue or fatigue, and loss of interest in sex (Finger, 2008).

The BDI consists of a self-report questionnaire with 21 premises, referring to the current moment of the subject and quantified in a scale of 4 intensity points ( 0 to 3$)$. The purpose of this scale is to evaluate the symptomatology of depression. It is an instrument of easy manipulation and application, besides having great acceptance. Scores range from zero to 63, where zero indicates no trace of depressive symptoms, while the higher score indicates greater severity of symptoms. The interpretation guide is as follows: (a) 0 = no depression; (b) 10 to $16=$ indicates a state of mild depression; (c) 17 to $29=$ comprises a state of moderate depression; and (d) 30 to 63 = indicates a state of severe depression. BDI can be applied in individuals aged 13 years or over (Finger, ARGIMON, 2013).

The research was carried out at the Metropolitan Amazonian Faculty (FAMAZ), which is a private higher education institution integrated to the Euro-American Educational Group, based in Belém do Pará, Brazil, with students from the 1 st, 4 th and 8 th nursing courses ${ }^{\circ}$ periods.

Initially a pre-contact was made with the coordination responsible for the nursing course to authorize the data collection of our research.

The research was submitted to the approval of the research ethics committee (CEP), institutional consent and signing of the informed consent form, which were clarified about the objectives of the study and acceptability in participating in the research, of the instrument. The data collection was done in classrooms, at a schedule previously scheduled with the students and teachers and with the consent of the course coordination.

\section{RESULTS}

The research was carried out in September 2015, with students of the first, fourth and eighth periods, the afternoon and evening shifts of the Nursing Course of the Amazon Metropolitan College (FAMAZ). The total number of academics enrolled in the course and who are regularly attending the above mentioned periods is 217, of these 147 participated, 57 were not in college, 13 refused to participate in the application of the Beck - IDB Depression Inventory.

More than $53 \%$ of the participants presented symptoms of depression, of which $28.57 \%$ presented symptoms of mild depression, $21.08 \%$ had symptoms of moderate depression, and $3.40 \%$ presented severe depression. (Table 1).

Table 1. Classification of symptoms among research participants (2015) 


\begin{tabular}{|c|c|c|c|}
\hline IDB & $\begin{array}{c}\text { Absolute } \\
\text { Frequency }\end{array}$ & $\begin{array}{c}\text { Percentage } \\
\text { Frequency }\end{array}$ & $\begin{array}{c}\text { Cumulative } \\
\text { frequency }\end{array}$ \\
\hline No Depressive Symptoms & 69 & $46.94 \%$ & $100 \%$ \\
\hline Light Symptoms & 42 & $28.57 \%$ & $53.05 \%$ \\
\hline Symptoms Moderate & 31 & $21.08 \%$ & $24.48 \%$ \\
\hline Severe Symptoms & 5 & $3.40 \%$ & $3.40 \%$ \\
\hline TOTAL & 147 & $100 \%$ & - \\
\hline
\end{tabular}

\section{Characteristics of participants}

The majority of participants $(56.46 \%)$ were young adults, aged up to 29 years (RCT, 2013). Regarding the gender of the participants, the highest trend was female $(\mathrm{F})$ with $85.03 \%$, which corresponds to more than five women for each man $(\mathrm{M})$ of the course, considering the ratio $(\mathrm{F} / \mathrm{M})$ of 5,68 . The variation in the age of the men is between 18 and 48 years, with a mean of 27.81 years and a standard deviation of 9.07 , while the female is between 17 and 53 years, with a mean of 28.18 years and deviation standard of 8.29 .

Most of the research participants do not practice nursing technician activity (58.5\%). The distribution of participants per semester was balanced, considering the afternoon and evening shifts, with $30.61 \%$ of participants in the first period, $38.77 \%$ of fourth period students and $32.65 \%$ of students in the eighth period (Table 2) .

Table 2. Descriptive analysis of the characteristic data.

SEX 